\title{
Phenylephrine Bitartrate
}

National Cancer Institute

\section{Source}

National Cancer Institute. Phenylephrine Bitartrate. NCI Thesaurus. Code C66378.

The bitartrate salt form of phenylephrine, a direct-acting sympathomimetic amine chemically related to adrenaline and ephedrine with potent vasoconstricting activity. Phenylephrine is a post-synaptic alpha-adrenergic receptor agonist that causes vasoconstriction, increases systolic/diastolic pressures, reflex bradycardia, and increases stroke output. 